\title{
Structural Change Accounting with Labor Market Distortions
}

\author{
Wenbiao Cai \\ Department of Economics Working Paper Number: 2014-03

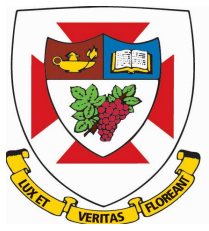

THE UNIVERSITY OF WINNIPEG

Department of Economics

515 Portage Avenue

Winnipeg, Canada R3B 2E9

This working paper is available for download at:

http://ideas.repec.org/s/win/winwop.html 


\title{
Structural Change Accounting with Labor Market Distortions
}

\author{
Wenbiao Cai*
}

October 2014

\begin{abstract}
This paper quantifies the relative importance of sectoral productivity and labor market distortions for structural change. I use a model in which labor productivity is the product of TFP and human capital in each sector, but distortions generate wedges in wage per efficiency worker across sectors. I calculate human capital by sector using micro census data, and use the model to infer TFP and distortions such that it replicates structural change in the US, India, Mexico and Brazil between 1960 and 2005. I find that (1) TFP growth in agriculture drives most of the decline in its share of labor; (2) the role of labor market distortions is limited.
\end{abstract}

JEL codes: O11; O41; J31

Keywords: Structural Change; Productivity; Distortions

I am indebted to Manish Pandey for extensive discussions and insightful comments. Thanks also go to James Townsend and seminar participants at the University of Winnipeg. All errors are my own.

*Department of Economics, University of Winnipeg. 515 Portage Avenue, Winnipeg, Manitoba, R3B2E9, Canada. Phone: 1-204-258-2984; fax: 1-204-772-4183; email: we.cai@uwinnipeg.ca. 


\section{Introduction}

Structural change - continued labor migration out of agriculture - is a universal characteristic of economic development. In standard models, structural change is driven by sectoral productivity growth (Kongsamut et al., 2001; Ngai and Pissarides, 2007). An important question is, thus, to identify the relative importance of productivity growth in different sectors for structural change in the data. Papers like Gollin et al. (2007), Duarte and Restuccia (2010) and Alvarez-Cuadrado and Poschke (2011) are examples along this line of inquiry. These papers, however, often have difficulty accounting for the fact that employment shares and output shares differ significantly in the process of structural change. Buera and Kaboski (2009) note this feature and suggest that distortions to inter-sectoral allocation of factors of production are a possible explanation. ${ }^{1}$

Labor market distortions in the form of barriers to labor moving across sectors are common in developing countries. ${ }^{2}$ I construct a model of structural change that incorporates this kind of labor market distortions. The model can account for simultaneously the dynamics of employment and output at the sector level in the data. I then use the model to quantify (1) the relative importance of productivity growth in agriculture visà-vis outside agriculture for structural change and (2) the effects of labor market distortions on sectoral employment and aggregate output.

Central to the inquiry is how labor market distortions are measured. Since these distortions are not directly observed, a common approach is to use a model to infer their magnitude. For example, in Restuccia et al. (2008) labor market distortions are mapped into differences in wage per worker across sectors. The upshot then is that these distortions significantly slow down the process of structural change. In contrast,

\footnotetext{
${ }^{1}$ Others argue that employment or output are simply mismeasured, e.g., Gollin, Parente, and Rogerson (2004), Herrendorf and Schoellman (2012), Cai and Pandey (2013a).

${ }^{2}$ Often cited examples are the hukou system in China and labor regulations in India manufacturing (Besley and Burgess, 2004).
} 
Herrendorf and Schoellman (2014) use individual-level data to show that human capital accounts for most of the sectoral wage gap and derive bounds for the magnitude of distortions. ${ }^{3}$ This paper combines both approaches. I use a model to infer labor market distortions and evaluate their importance as in Restuccia et al. (2008) and take into account explicitly sectoral differences in human capital as in Herrendorf and Schoellman (2014). I apply the model to the growth experience of the US, India, Mexico, and Brazil over the period 1960-2005. The US is a useful benchmark as it is commonly regarded as a frictionless economy. The other three countries are developing countries that account for 22 percent of world population in 2005; these countries experienced fast economic growth and significant structural change over the reference period. For all countries, another selection criteria is to have sufficiently detailed census data available from IPUMSInternational that allows the calculation of human capital by sector for multiple periods.

The model economy has three sectors: agriculture, manufacturing, and services. Preferences are non-homothetic. Production technology in each sector is a linear combination of total factor productivity (TFP) and efficiency worker, the latter the product of human capital and physical labor. There are exogenous distortions in the labor market that generate wedges in wage per efficiency worker across sectors. These wedges are a catchall for barriers to labor moving across sectors such as taxes, labor regulations, or migration costs.

The model is very parsimonious; it has six preference parameters and three exogenous sequences: TFP, human capital, and wage wedges. Some preference parameters are taken directly from the literature while others are calibrated to match relevant moments in the data. I calculate human capital using micro census data of individual countries that are harmonized by IPUMS. This calculation involves two steps. First, I regress

\footnotetext{
${ }^{3}$ However, for the lack of counterfactuals it is unclear in their paper the quantitative effects of the derived distortions on aspects of structural change such as labor allocation across sectors.
} 
the logarithm of wage for employees on their years of schooling, experience, and gender. This regression is run separately for each sector and for each country. In other words, the Mincer returns to schooling and experience are country- and sector-specific. Second, I use the recovered Mincer returns to compute human capital for all workers in a sector (both employees and self-employed) and for each country. I find that in every country agriculture is the sector with the lowest human capital. Sectoral differences in human capital are also much larger in India, Mexico, and Brazil than in the US.

Given preferences and human capital, I use the model to infer TFP for each sector and wage wedges following the methodology outlined in Chari, Kehoe, and McGrattan (2007). Specifically, I choose the sequence of TFP for each sector and the sequence of wage wedges such that the model delivers time paths of sectoral shares of labor, sectoral shares of value added, and aggregate GDP per worker that exactly match their data counterparts. In other words, the model by construction replicates the process of structural change in each country.

For the US, the accounting exercise yields wage wedges that are close to zero. In other words, labor market in the US is largely frictionless through the lens of the model. For other countries, the accounting exercise implies significant wedges in wage per efficiency worker both between agriculture and manufacturing and between services and manufacturing. That is, labor markets in these countries are subject to systematic distortions through the lens of the model. For example, the wedges imply that an individual working in agriculture earns half the wage of another identical individual working in manufacturing in Mexico and Brazil, and three-quarters in India. As a comparison, the magnitude of these distortions is similar to that derived in Herrendorf and Schoellman (2014). The accounting exercise also yields a sequence of TFP for each sector. I use relative prices of output in the data to discipline sectoral TFP derived from the model. It is reassuring that for all countries, the model generates changes in relative prices that are 
consistent with those in the data.

I now use the model to quantitatively evaluate the relative importance of sectoral TFP growth and distortions for structural change through a series of counterfactual experiments. In each experiment one exogenous variable is held constant at the initial value, while other exogenous variables remain unchanged. I then compare allocations from the counterfactual economy against those in the data. There are two main findings. First, TFP growth in agriculture drives most of the decline in its share of labor. This result holds true for all countries despite very different levels of economic development. TFP growth in manufacturing and services, on the other hand, is more important for the growth of aggregate output than for labor migration out of agriculture. Second, labor market distortions slow the speed at which labor moves out of agriculture and generate losses in aggregate output. These effects, however, are quantitatively small. Removing the distortions can at the most speed up labor migration out of agriculture by 0.6 percent annually. The gain in aggregate output through the removal of labor market distortions averages 4 percent. Thus, the overall effects of labor market distortions are quite limited.

The relative importance of sectoral productivity growth for structural change depends on, broadly speaking, whether consumption goods produced in different sectors are complements or substitutes. To assess robustness of the results, I consider two alternate scenarios: one in which consumption goods remain gross complements and the utility function is closer to Leontief; and the other one in which consumption goods are gross substitutes. In each case, I repeat the accounting exercise to infer TFP and wage wedges and then re-run the counterfactual experiments. I find that (1) TFP growth in agriculture remains the most important factor for labor migration out of agriculture and (2) the effects of labor market distortions remain small.

This paper is broadly related to the literature on structural change that is nicely summarized in Herrendorf, Rogerson, and Valentinyi (2013a). It adds to papers that seek 
to identify determinants of structural change. Alvarez-Cuadrado and Poschke (2011) use historical growth experience of industrialized countries and find that productivity growth outside agriculture is more important at early stages of development, while productivity growth in agriculture matters more at later stages. ${ }^{4}$ Duarte and Restuccia (2010) use a model to gauge the importance of structural change in explaining the convergence of income per worker between late starters and the United States. This paper complements these papers by considering the role of labor market distortions.

Several other papers also incorporate inter-sectoral distortions in a model of structural change. Cai and Pandey (2013b) focus specifically on the size-dependent labor regulations in India manufacturing. Using a two-sector model, they find that these regulations generate the "missing middle" feature of the size distribution of manufacturing establishments, but have limited impact on sectoral employment and aggregate output. Swiecki (2013) incorporates inter-sectoral distortions and international trade into a model of structural change to identify the determinants of structural change for a large set of countries. An important difference, however, is that Swiecki (2013) does not consider sectoral difference in human capital and instead measures distortions as sectoral gaps in value added per worker. This likely overstates the magnitude of distortions because Gollin et al. (2013) show that the productivity gap between agriculture and nonagriculture is mostly accounted for by human capital. Similar to this paper, Vollrath (2013) also finds that the gain in aggregate output through better allocation of human capital across sectors is small. This paper further shows that labor market distortions have limited impact on sectoral employment.

This paper also relates to papers that use the accounting method in Chari et al. (2007) to study structural change. Cheremukhin et al. (2013) study the historical growth and

\footnotetext{
${ }^{4}$ Dennis and Iscan (2009) instead test the relative importance of two mechanisms: non-homothetic preferences and sector-biased productivity growth. US data reveals that the first mechanism dominates prior to 1950 and the second one is more important after.
} 
structural change of Russia and provide estimates for the welfare costs of policies under the Stalin regime. Cheremukhin et al. (2014) focus on the economic development and structural change of China after 1953. Similar to this paper, the authors also find that productivity growth in agriculture is the most important factor for China's structural change.

This paper complements existing papers on structural change of individual countries. Examples are Dekle and Vandenbroucke (2012) and Cao and Birchenall (2013) for China; Machicado et al. (2012) for Latin American countries; Teignier (2012), Sposi (2012), Uy, Yi, and Zhang (2013), and Betts, Giri, and Verma (2013) for Korea; and Verma (2012) for India.

The remainder of this paper is organized as follows. Section 2 introduces the model. Section 3 presents the quantitative results. Section 4 concludes.

\section{Model}

Environment The economy has a stand-in household that comprises of measure one identical members. Each member is endowed with one unit of physical labor that is supplied inelastically. The household's utility function is given by

$$
U\left(c_{a}, c_{m}, c_{s}\right)=\left[\gamma_{a}\left(c_{a}-\overline{c_{a}}\right)^{\frac{\varepsilon-1}{\varepsilon}}+\gamma_{m}\left(c_{m}\right)^{\frac{\varepsilon-1}{\varepsilon}}+\gamma_{s}\left(c_{s}+\overline{c_{s}}\right)^{\frac{\varepsilon-1}{\varepsilon}}\right]^{\frac{\varepsilon}{\varepsilon-1}},
$$

where $c_{a}, c_{m}, c_{s}$ is consumption good produced in agriculture, manufacturing, and services, respectively. Preferences are non-homothetic and $\overline{c_{a}}>0, \overline{c_{s}}>0$. The weights on consumption goods are such that $0<\gamma_{i}<1$, and $\sum \gamma_{i}=1$. The parameter $\varepsilon$ governs the elasticity of substitution between consumption goods.

Output in sector $i$ is produced by a representative firm using the following technol- 
ogy:

$$
y_{i}=A_{i} E_{i},
$$

where $y_{i}$ is output, $A_{i}$ is total factor productivity (TFP), $E_{i}=h_{i} n_{i}$ is efficiency worker, $h_{i}$ is human capital and $n_{i}$ is physical labor. Firms hire labor at wage per efficiency worker $w_{i}$, and sell output at price $p_{i}$.

The labor market is subject to distortions. I follow Restuccia et al. (2008) and model these distortions as wedges in wage across sectors. The difference here is that the wedge is between wage per efficiency worker instead of wage per worker. Specifically, I assume that $w_{a}=\left(1-\phi_{a}\right) w_{m}$ and $w_{s}=\left(1-\phi_{s}\right) w_{m}$, where $\phi_{a}<1$ and $\phi_{s}<1$. The parameters $\phi_{a}$ and $\phi_{s}$ capture the wage wedges across sectors. These wedges are a catch-all for barriers to labor moving across sectors such as taxes, labor regulations, or migration costs.

Optimization At time $t$, the household chooses the allocation of efficiency worker across sectors $\left(N_{a t}, N_{m t}, N_{s t}\right)$ and consumption bundle $\left(c_{a t}, c_{m t}, c_{s t}\right)$ to maximize household utility. The household's problem at time $t$ is as follows:

$$
\begin{aligned}
\max _{\left\{c_{a t}, c_{m t}, c_{s t}, N_{a t}, N_{m t}, N_{s t}\right\}} & U\left(c_{a t}, c_{m t}, c_{s t}\right) \\
\text { s.t. : } & \sum p_{i t} c_{i t}=\sum w_{i t} N_{i t}, \\
& N_{i t}=h_{i t} n_{i t}, \sum n_{i t}=1 .
\end{aligned}
$$

where $p_{i t}$ is the price of output produced in sector $i$ and $n_{i t}$ is the measure of physical labor allocated to that sector at time $t$. For simplicity, there is no savings. Hence, the household solves a sequence of static problems.

The representative firm in sector $i$ chooses the amount of efficiency labor to maximize 
profit, i.e.,

$$
\begin{aligned}
& \max _{\left\{E_{i t}\right\}} \quad p_{i t} y_{i t}-w_{i t} E_{i t}, \\
& \text { s.t.: } \quad E_{i t} \geq 0 .
\end{aligned}
$$

The goods market clearing conditions are

$$
c_{a t}=A_{a t} E_{a t}, \quad c_{m t}=A_{m t} E_{m t}, \quad c_{s t}=A_{s t} E_{s t} .
$$

The labor market clearing conditions are

$$
E_{a t}=N_{a t}, \quad E_{m t}=N_{m t}, \quad E_{s t}=N_{s t}
$$

Equilibrium A competitive equilibrium is a set of prices $\left\{p_{a t}, p_{m t}, p_{s t}, w_{a t}, w_{m t}, w_{s t}\right\}$, allocations for the stand-in household $\left\{c_{a t}, c_{m t}, c_{s t}, N_{a t}, N_{m t}, N_{s t}\right\}$, and allocations for the firm $\left\{E_{a t}, E_{m t}, E_{s t}\right\}$ such that (i) given prices, $\left\{c_{a t}, c_{m t}, c_{s t}, N_{a t}, N_{m t}, N_{s t}\right\}$ solve household's optimization problem in (1); (ii) given prices, $\left\{E_{a t}, E_{m t}, E_{s t}\right\}$ solve the firm's profit maximization problem in (2); and (iii) markets clear: equations (3) to (4) hold.

The first order conditions for the firm's profit maximization yield the following expression for wages and prices of output in agriculture and services relative to manufacturing:

$$
w_{m t}=p_{m t} A_{m t}, \frac{p_{a t}}{p_{m t}}=\frac{\left(1-\phi_{a t}\right) A_{m t}}{A_{a t}}, \frac{p_{s t}}{p_{m t}}=\frac{\left(1-\phi_{s t}\right) A_{m t}}{A_{s t}} .
$$


The optimal consumption bundle is given by the following equations:

$$
\begin{aligned}
& \frac{c_{a t}-\overline{c_{a}}}{c_{m t}}=\left(\frac{\gamma_{a}}{\gamma_{m}}\right)^{\varepsilon}\left(\frac{p_{m t}}{p_{a t}}\right)^{\varepsilon}, \\
& \frac{c_{s t}+\overline{c_{s}}}{c_{m t}}=\left(\frac{\gamma_{s}}{\gamma_{m}}\right)^{\varepsilon}\left(\frac{p_{m t}}{p_{s t}}\right)^{\varepsilon} .
\end{aligned}
$$

The equilibrium admits a closed-form solution. Using first-order conditions (5) and the market clearing conditions (3) and (4), the optimal consumption allocation implies

$$
\begin{aligned}
& \frac{A_{a t} h_{a t} n_{a t}-\overline{c_{a}}}{A_{m t} h_{m t} n_{m t}}=\left(\frac{\gamma_{a}}{\gamma_{m}}\right)^{\varepsilon}\left(\frac{A_{a t}}{\left(1-\phi_{a t}\right) A_{m t}}\right)^{\varepsilon}, \\
& \frac{A_{s t} h_{s t} n_{s t}+\overline{c_{s}}}{A_{m t} h_{m t} n_{m t}}=\left(\frac{\gamma_{s}}{\gamma_{m}}\right)^{\varepsilon}\left(\frac{A_{s t}}{\left(1-\phi_{s t}\right) A_{m t}}\right)^{\varepsilon} .
\end{aligned}
$$

The two equations above, together with the resources constraint $n_{a t}+n_{m t}+n_{s t}=1$, yields the share of physical labor in agriculture at time $t$ as

$$
n_{a t}=\frac{1+\frac{\overline{c_{s}}}{A_{s t} h_{s t}}-\frac{\overline{c_{a}}}{A_{a t} h_{a t}}}{1+\left(\frac{\left(1-\phi_{a t}\right) \gamma_{m}}{\gamma_{a}}\right)^{\varepsilon}\left(\frac{A_{a t}}{A_{m t}}\right)^{1-\varepsilon}\left(\frac{h_{a t}}{h_{m t}}\right)+\left(\frac{\left(1-\phi_{a t}\right) \gamma_{s}}{\left(1-\phi_{s t}\right) \gamma_{a}}\right)^{\varepsilon}\left(\frac{A_{a t}}{A_{s t}}\right)^{1-\varepsilon}\left(\frac{h_{a t}}{h_{s t}}\right)}+\frac{\overline{\mathcal{C}_{a}}}{A_{a t} h_{a t}} .
$$

The mechanisms driving structural change are transparent in Equation (8). First, it encompasses two standard mechanisms highlighted in the literature: non-homothetic preferences and sector-biased technological change. Consider, for example, an increase in agricultural TFP $\left(A_{a t}\right)$. The income effect dictates that higher income leads to a lower share of expenditure on agricultural goods, and correspondingly, a smaller share of labor in agriculture. This channel operates through the term $\left(\overline{c_{a}} /\left(A_{a t} h_{a t}\right)\right)$. The relative price effect depends on the elasticity of substitution between consumption goods. If consumption goods are gross complements $(\varepsilon<1)$, then expenditure shifts (and labor moves) towards the sector with lower productivity growth. In this case, faster growth of TFP in agriculture speeds up labor migration out of agriculture. If consumption goods are 
gross substitutes $(\varepsilon>1)$, faster growth of TFP in agriculture slows down labor migration out of agriculture. The relative price effect operates through the terms $\left(A_{a t} / A_{m t}\right)^{1-\varepsilon}$ and $\left(A_{a t} / A_{s t}\right)^{1-\varepsilon}$.

Second, labor migration out of agriculture is subject to barriers that are captured by the wage wedges. Consider the wedge in wage per efficiency worker between agriculture and manufacturing $\left(\phi_{a t}\right)$. This can be thought of as a tax on earnings of workers who move out of agriculture into manufacturing. And everything else the same, a lower tax (or equivalently, a lower wedge) would increase the flow of workers from agriculture to manufacturing. This is what Equation (8) shows: as $\phi_{a t}$ decreases, the share of labor in agriculture declines.

\section{Quantitative Analysis}

Annual data on employment and value added by sector is from the GGDC 10-sector database (Timmer and de Vries, 2009). ${ }^{5}$ I map the ten industries in the data to the three sectors in the model as follows. The agriculture sector is the sum of agriculture, forestry, and fishing. The manufacturing sector is the sum of mining, quarrying and manufacturing. And the services sector comprises of all remaining industries.

To compute human capital, I use micro data from census of individual countries that are harmonized by IPUMS-International (2014). The minimum requirement for a sample is to have information on wage and salary income, class of worker (employees or selfemployed), hours of work, industry, core demographics, and educational attainment. Between 1960 and 2005, there are five samples for India and Brazil, and six for Mexico. For the US, samples are March supplements to Current Population Survey.

I follow the procedures in Herrendorf and Schoellman (2014) to calculate human cap-

\footnotetext{
${ }^{5}$ For Brazil, value added shares are from the World Development Indicators.
} 
ital by sector. This calculation involves two steps. First, I regress the logarithm of wage on years of schooling, experience, and gender. It is important to note that (1) these wage regressions involve only employees in each sector, because self-employed individuals do not report wage; (2) for each country, these wage regressions are run separately for agriculture, manufacturing and services. Hence, the Mincer returns to schooling and experience are country- and sector-specific. And the regressions suggest that the Mincer returns to schooling are systematically lower in agriculture than in manufacturing and in services. Second, I use the recovered Mincer returns to compute human capital for all individuals (both employees and self-employed) in each sector. The implicit assumption is that in each sector a self-employed with characteristics that are the same as an employee would have earned the same wage. Further detail on human capital calculation is delegated to section A of the Appendix.

These sectoral human capital estimates are extended into an annual series using cubic-spline interpolation. Since production technology is linear, it is convenient to normalize average human capital in manufacturing to be one and express human capital in agriculture and services relative to that in manufacturing. Table 1 shows that in all countries, agriculture is the sector with the least average human capital. In Brazil and the US, average human capital is the highest in manufacturing. In India and Mexico, services is the sector with the highest human capital. Moreover, the human capital gap between agriculture and the rest of the economy is quite large - average human capital in nonagriculture is three times that in agriculture in India and Brazil. Even in the US, the gap is close to a factor of 1.5 .

\subsection{Calibration}

In this section I describe how model parameters are determined. The utility function is identical to that in Herrendorf et al. (2013b), in which the authors emphasize the impor- 
Table 1: Human Capital in Agriculture and Services relative to Manufacturing

\begin{tabular}{lcc}
\hline Country & \multicolumn{2}{c}{ Average Human Capital } \\
\cline { 2 - 3 } & Agri./Manu. & Serv./Manu. \\
\hline India & 0.38 & 1.29 \\
Mexico & 0.56 & 1.09 \\
Brazil & 0.36 & 0.96 \\
US & 0.60 & 0.83 \\
\hline
\end{tabular}

tance of consistent mapping between preferences and technology. Since technology is defined over value added in this paper, the appropriate domain of preferences is value added components of final consumption. Under the value-added specification of preferences, they estimate the consumption weights as follow: $\gamma_{a}=0.01, \gamma_{m}=0.18, \gamma_{s}=0.81$. I adopt the same values here. For the elasticity of substitution, there is more variation in its values. Herrendorf et al. (2013b) report that a value close to zero produces the best fit to post-war US data, which appears rather extreme as utility function in this case is Leontief. Buera and Kaboski (2009) instead suggest that an elasticity of 0.5 is more plausible and produces a good fit to US data dating back to 1870. Acemoglu and Guerrieri (2008) use a higher value of 0.75. For studying Korea's structural change, Uy et al. (2013) and Betts et al. (2013) also use an elasticity of substitution that is around 0.75 . I set $\varepsilon=0.75$ as a first pass, and later experiment with different values to check robustness.

There remains two preference parameters $\left(\overline{c_{a}}, \overline{s_{s}}\right)$ whose values need to be determined. A common strategy in the literature is to choose values for these preference parameters to match sectoral shares of labor or value added. This approach is not followed here. The reason is that sectoral shares of labor and value added will later on be used to pin down the sequence of TFP and wage wedges for each country. As a result, these moments in the data cannot be used to discipline the values for $\overline{c_{a}}$ and $\overline{c_{s}}$.

Instead, I calibrate these two parameters to relative prices of output in 1980 India. I proceed as follows. For a given choice of $\overline{c_{a}}$ and $\overline{c_{s}}$, I pick levels of TFP and wage 
wedges such that the model exactly matches the sectoral shares of labor and value added observed in 1980 India data. The model then implies a particular set of relative prices of output: that between agriculture and manufacturing and that between services and manufacturing. Then the program searches for combinations of $\overline{c_{a}}$ and $\overline{c_{s}}$ such that the model also matches these relative prices in the data.

In principle, the calibration could be applied to any country with relative price data. India proves to be a convenient case for two reasons. First, India has a significant share of labor in agriculture in 1980. For such an economy, the calibration produces a tighter estimate for $\overline{c_{a}}$ and $\overline{c_{s}}$, because when income is low the share of labor in agriculture in the model is quite sensitive to the values for $\overline{c_{a}}$ and $\overline{c_{s}}$. This would not be the case if, for example, these values are calibrated to the US, where agriculture is almost a negligible component of the economy. Second, there is data for India to discipline other implications from the model that are not targeted in calibration. Rosenzweig and Wolpin (1993) and Atkeson and Ogaki (1996) report that the subsistence consumption share of expenditure is about 33 percent for India. The calibration of $\overline{c_{a}}$ produces a subsistence share of income that is 27 percent. This approach of using expenditure data to discipline the subsistence parameter is also used in Lagakos and Waugh (2013).

\subsection{Accounting for Structural Change}

The model has three exogenous processes: human capital, TFP, and wage wedges. Human capital is calculated from census data. There remains a sequence of TFP $\left\{A_{a t}, A_{m t}, A_{s t}\right\}$ and a sequence of wage wedges $\left\{\phi_{a t}, \phi_{s t}\right\}$ that need to be determined. The basic idea is to pick these sequences such that the model exactly matches the time path of sectoral shares of labor, sectoral shares of value added, and real aggregate GDP per worker observed in the data.

Labor allocation in the model are given by equations (6) to (8). The share of value 
added in sector $i$, denoted by $v_{i t}$, is simply given by

$$
v_{i t}=\frac{p_{i t} y_{i t}}{\sum_{i} p_{i t} y_{i t}} .
$$

Real aggregate GDP per worker is $y_{t}=\sum_{i} p_{i} y_{i t}$, where $p_{i}$ is price of output for a reference year. Note that $\left\{n_{i t}, v_{i t}, y_{t}\right\}$ are functions of only TFP, wage wedges, and other known model parameters.

Let $\hat{x}$ denote the data counterpart of variable $x$ in the model. To back out the sequence of TFP and wage wedges, I solve the following system of equations:

$$
\begin{aligned}
& n_{i t}\left(A_{a t}, A_{m t}, A_{s t}, \phi_{a t}, \phi_{s t} \mid \Omega, h_{a t}, h_{m t}, h_{s t}\right)=\hat{n}_{i t}, \quad i=a, s \\
& v_{i t}\left(A_{a t}, A_{m t}, A_{s t}, \phi_{a t}, \phi_{s t} \mid \Omega, h_{a t}, h_{m t}, h_{s t}\right)=\hat{v}_{i t}, \quad i=a, s \\
& y_{t}\left(A_{a t}, A_{m t}, A_{s t}, \phi_{a t}, \phi_{s t} \mid \Omega, h_{a t}, h_{m t}, h_{s t}\right)=\hat{y}_{t},
\end{aligned}
$$

where $\Omega=\left\{\omega_{a}, \omega_{m}, \omega_{s}, \rho, \overline{c_{a}}, \overline{c_{s}}\right\}$ is the set of preference parameters that are calibrated in section 3.1 and $h_{i}$ is human capital in sector $i$. The first two equations imply that the model matches the share of labor as well as the share of value added in agriculture and services. By market clearing, the model also matches the share of labor and the share of value added in manufacturing. The last equation implies that the model matches real aggregate GDP per worker in the data.

Table 2 presents for each country the mean and standard deviation of the inferred wage wedges ( $\phi_{a t}$ and $\phi_{s t}$ ) over the sample periods. Several observations are noteworthy. I begin with the last row that represents the case of the US. The accounting exercise yields a wedge in wage per efficiency worker between agriculture and manufacturing that averages -0.18 , while that between manufacturing and services is practically zero. Since manufacturing and services together account for more than 95 percent of labor and 
GDP in the US through out the entire sample period, I conclude that the labor market in the US is largely frictionless through the lens of the model.

Unlike that in the US, rows 1-3 of Table 2 show that for India, Mexico and Brazil there are large wedges in wage per efficiency worker both between agriculture and manufacturing and between services and manufacturing. In other words, through the lens of the model labor market distortions are systematic in these countries. First, the wedges suggest that wage per efficiency worker is significantly lower in agriculture than in manufacturing and services. An individual in agriculture earns roughly half the wage of an identical individual in manufacturing in Mexico and Brazil, and three-quarters in India. The magnitude of these distortions is similar to that Herrendorf and Schoellman (2014) derive for a larger set of countries including India, Mexico and Brazil. Second, unlike the case of the US, there are significant wage wedges also between manufacturing and services. In Mexico and India, wage per efficiency worker is higher in services than in manufacturing while the reverse is true in Brazil. In Summary, the accounting exercise suggests that labor markets in India, Mexico and Brazil are far from frictionless.

Table 2: Wage Wedges between Agriculture (Services) and Manufacturing

\begin{tabular}{lcccc}
\hline Country & \multicolumn{2}{c}{$\left(\phi_{a}\right)$} & \multicolumn{2}{c}{$\left(\phi_{s}\right)$} \\
\cline { 2 - 5 } & Mean & Std. & Mean & Std. \\
\hline India & 0.22 & 0.07 & -0.08 & 0.12 \\
Mexico & 0.51 & 0.05 & -0.31 & 0.29 \\
Brazil & 0.55 & 0.08 & 0.30 & 0.16 \\
US & -0.18 & 0.24 & -0.007 & 0.06 \\
\hline
\end{tabular}

The accounting exercise also yields a sequence of TFP for each sector. It is observed from Equation (5) that TFP and wage wedges together imply a particular sequence of relative prices of output. Like in Alvarez-Cuadrado and Poschke (2011) and Duarte and Restuccia (2010), I use the relative prices of output in the data to discipline TFP for each sector in the model. For this purpose, Table 3 presents the annual percent- 
age growth of the price of output in agriculture and services (relative to that in manufacturing) in the data and in the model. To derive the price level of output by sector in the data, I divide value added in current prices by the value added in constant prices. ${ }^{6}$ These price levels are then used to calculate the relative prices and their growth rates. It is reassuring that the model delivers changes in relative prices that are consistent with those in the data. For example, the relative price of services has been increasing in all countries and that of agriculture has been increasing in all countries except Mexico. The model generates both observations. It is also observed the magnitude of changes in the model is generally larger than that in the data.

Table 3: Annual Percentage Growth of Price relative to Manufacturing

\begin{tabular}{lcccc}
\hline Country & \multicolumn{2}{c}{ Agriculture } & \multicolumn{2}{c}{ Services } \\
\cline { 2 - 5 } & Data & Model & Data & Model \\
\hline India & 1.3 & 4.6 & 1.4 & 7.3 \\
Mexico & -0.8 & -3.0 & 0.5 & 1.5 \\
US & 0.4 & 1.1 & 1.9 & 7.9 \\
\hline
\end{tabular}

\subsection{Counterfactual Experiments}

Now I use the model to quantitatively evaluate the relative importance of sectoral TFP and labor market distortions for structural change. In general, to isolate the marginal effects of a particular exogenous variable, I keep the variable constant over time while the other variables remain the same. Then I compare allocations from the counterfactual economy against those in the data. To facilitate comparison, in each counterfactual experiment I calculate the (annualized) changes in sectoral shares of labor and real aggregate GDP per worker between the first and the last period.

\footnotetext{
${ }^{6}$ Data on value added in current prices are not available for Brazil until 1990. This precludes Brazil from the calculation of relative prices.
} 
India Table 4 summarizes the results for India. The second row corresponds to the counterfactual experiment where TFP in agriculture is held constant. The most visible effect is on labor allocation across sectors. Shutting down TFP growth in agriculture actually implies that, contrary to the data, labor moves from manufacturing and services into agriculture over time. The share of labor in agriculture increases 0.15 percent annually in the counterfactual economy, whereas in the data it declines 0.6 percent annually. As more and more labor move into a sector with no growth in TFP, real aggregate GDP per worker is growing at roughly half the rate in the data (1.65 percent vs. 2.94 percent).

Table 4: Allocations in Counterfactual Economy: India

\begin{tabular}{lccccc}
\hline & \multicolumn{3}{c}{ Changes in Share of Labor } & $\begin{array}{c}\text { Changes in } \\
\text { GDP per worker }\end{array}$ \\
\cline { 2 - 4 } & Agri. & Manu. & Serv. & 2.94 \\
\hline Data & -0.60 & 0.95 & 1.40 & 1.65 \\
No TFP Growth in Agriculture & 0.15 & -0.56 & -0.35 & 1.62 \\
No TFP Growth in Manufacturing & -0.64 & 1.89 & 1.00 & 2.48 \\
No TFP Growth in Services & -0.61 & 0.86 & 1.47 & 3.02 \\
\hline
\end{tabular}

When TFP in manufacturing is held constant, as presented in the third row of Table 4, two implications follow. On the one hand, there is the most reduction in real aggregate GDP per worker. On the other hand, labor is moving from both agriculture and services to manufacturing. The rate at which labor migrates out of agriculture, however, is only marginally different from that in the data. In other words, TFP growth in manufacturing has little impact on labor migration out of agriculture, but has a sizeable impact on the final destination of the migrated labor from agriculture. In the counterfactual, manufacturing absorbs most of the labor from agriculture, while in the data services does. 
The fourth row of Table 4 shows that shutting down TFP growth in services delivers results similar to those when TFP in manufacturing is held constant. In both cases, it is observed that (i) labor moves out of agriculture faster; (ii) the sector with lower TFP growth absorbs most of the migrated labor from agriculture; and (iii) the growth rate of aggregate GDP per worker is substantially reduced.

The first three counterfactual experiments, thus, suggest that in the presence of wage wedges, TFP growth in agriculture is the most important factor for labor migration out of agriculture. Now I ask the reverse: given sectoral productivity growth, how would allocations look different if wage wedges are removed? This is summarized in the last row of Table 4. In this counterfactual economy, there are no distortions in the labor market and wage per efficiency worker is equalized across sectors, i.e., $\phi_{a t}=\phi_{s t}=0$. First of all, the gain in aggregate output from removing labor market distortions is small - real aggregate GDP per worker grows faster by 0.1 percent annually (or a 4 percent gain over 40 years). Similarly, Vollrath (2013) finds that the gain in output from better allocation of human capital across sectors is around 5 percent. Second, labor moves out of agriculture faster by 0.1 percent annually in the frictionless economy than in the data. That is, the effect of labor market distortions on labor migration out of agriculture is quite limited as well.

United States, Mexico and Brazil I repeat the same set of counterfactual experiments for the United States, Mexico and Brazil. The results are summarized in Table 5. Panel A compares the changes in the share of labor in agriculture. Panel B compares the changes in aggregate GDP per worker.

The messages from Table 5 are, broadly speaking, similar to those from Table 4 . TFP growth in agriculture has the most impact on labor migration out of agriculture. Once TFP growth in agriculture is disallowed, labor stops moving from agriculture to 
Table 5: Allocations in Counterfactual Economy: US, Mexico and Brazil

\begin{tabular}{|c|c|c|c|}
\hline \multicolumn{4}{|l|}{ Panel A: Changes in Share of Labor in Agriculture } \\
\hline & US & Mexico & Brazil \\
\hline Data & -2.95 & -2.45 & -2.46 \\
\hline No TFP Growth in Agriculture & 0.26 & 0.14 & -0.17 \\
\hline No TFP Growth in Manufacturing & -3.16 & -2.45 & -2.58 \\
\hline No TFP Growth in Services & -2.63 & -2.39 & -2.32 \\
\hline No Wage Wedges & -3.07 & -3.08 & -2.73 \\
\hline \multicolumn{4}{|l|}{ Panel B: Changes in GDP per worker } \\
\hline & US & Mexico & Brazil \\
\hline Data & 1.62 & 0.86 & 1.59 \\
\hline No TFP Growth in Agriculture & 0.63 & -0.52 & -0.02 \\
\hline No TFP Growth in Manufacturing & 0.38 & 0.81 & -0.09 \\
\hline No TFP Growth in Services & 2.38 & 1.21 & 2.82 \\
\hline No Wage Wedges & 1.65 & 0.93 & 1.75 \\
\hline
\end{tabular}

manufacturing and services and the reverse occurs in the case of the US and Mexico. In the case of Brazil, labor continues to move out of agriculture, but at a much reduced speed. Like in the case of India, TFP growth in manufacturing and services has very little impact on the share labor in agriculture.

In all three countries, removing wage wedges accelerates labor reallocation from agriculture to manufacturing and services. And the effect is the most significant in Mexico: labor moves out of agriculture faster by 0.6 percent annually in the frictionless economy than in the data. In the case of the US, the allocation of labor in the data is almost identical to that in the frictionless economy, again showing that labor market distortions in the US are minimal. 
Panel B documents the growth rate of aggregate GDP per worker in the counterfactual economies. The effects of sectoral TFP on aggregate GDP per worker vary across countries. For the US and Brazil, TFP growth in manufacturing is the most important for aggregate income growth. For Mexico, TFP growth in agriculture is the most important and TFP growth in manufacturing is borderline irrelevant. As in the case of India, while removing the wage wedges leads to positive gain in aggregate output in all countries, the gain is quantitatively small.

Perhaps a surprising observation from Panel B of Table 5 is that shutting down TFP growth in services, in fact, leads to faster growth of aggregate GDP per worker in all three countries. The reason is that for the model to match the employment shares and output shares in these countries, the sequence of TFP in services is such that it is declining over time. Hence, when TFP in services is held constant at the initial value, the counterfactual economies effectively have higher levels of TFP in the services sector and correspondingly higher output growth. It is also observed from Table 4 that this is not the case for India. Why would the accounting exercise produce a declining sequence of TFP in services for the US, Mexico and Brazil and an increasing one for India? The other three countries have income per worker that is many times higher than that in India even in 1960. For these countries, labor is driven into services mainly through the relative price effect. Since consumption goods are gross complements, for the model to generate continued flow of labor into services, TFP growth in services must be the slowest.

Two broad conclusions from these counterfactual experiments are, hence, as follow. First of all, TFP growth in agriculture is more important for labor migration out of agriculture than TFP growth outside agriculture. This of course is the view of development economists such as Rostow (1960). More recent papers like Gollin et al. (2002) and Duarte and Restuccia (2010) formalize and quantify the argument in equilibrium models of structural change. This paper further shows that the insights from these papers 
continue to hold when inter-sectoral labor allocation is subject to distortions. Second, labor market distortions generate losses in aggregate output and slow labor migration out of agriculture in all countries. However, the quantitative effects are found to be limited. Removing the distortions results in a 4-percent gain in aggregate output over 40 years and could at the most speed up labor migration out of agriculture by 0.6 percent annually. Consider the case of Mexico, where the effects of labor market distortions are the most pronounced. From 1960 to 2004, the share of labor in agriculture in Mexico declines from 52 percent to 17 percent in the data. In the counterfactual economy without frictions, the share would have declined to 12 percent by 2004.

\subsection{Different Elasticity of Substitution}

In this paper, structural change is triggered through two mechanisms: non-homothetic preferences and sector-biased productivity growth. The relative importance of these mechanisms hinges crucially on the elasticity of substitution between goods produced in different sectors. Consequently, the inference about the relative importance of sectoral TFP and labor market distortions might also vary with the elasticity of substitution.

Consider for example the case of shutting down TFP growth in agriculture. If consumption goods are gross compliments $(\varepsilon<1)$, then both the income effect and the relative price effect imply a higher share of expenditure on agricultural consumption goods, which leads to labor moving from manufacturing and services into agriculture. This is the result shown in the second row of Table 4. However, if consumption goods are gross substitutes $(\varepsilon>1)$, the income effect and the relative price effect works in opposite directions and the net effect depends on the relative strength of the two countervailing forces.

So far in the quantitative analysis I have assumed that $\varepsilon=0.75$, which implies that consumption goods are gross compliments. The question is, how robust are the results with respect to different elasticities? 
To answer this question, I experiment with two different values: $\varepsilon=0.5$ and $\varepsilon=1.5$. For each value of $\varepsilon$, I first repeat the accounting exercise described in Section 3.2 to infer wage wedges and TFP for each sector. Then I re-run the counterfactual experiments described in section 3.3. For exposition purposes, I focus only on the share of labor in agriculture as a metric for comparing allocations. In each counterfactual, I calculate the (annualized) changes in the share of labor in agriculture between the first and the last period. The results are summarized in Table 6.

Table 6: Share of Labor in Agriculture in Data and Counterfactual Economies

\begin{tabular}{lccc}
\hline India & $\varepsilon=0.5$ & Benchmark $(\varepsilon=0.75)$ & $\varepsilon=1.5$ \\
\hline Data & -0.6 & -0.60 & -0.6 \\
No TFP growth in Agriculture & 0.24 & 0.15 & 0.08 \\
No TFP growth in Manufacturing & -0.69 & -0.64 & -0.6 \\
No TFP growth in Services & -0.71 & -0.62 & -0.59 \\
No Wage Wedges & -0.79 & -0.73 & -0.61 \\
& & & \\
United States & $\varepsilon=0.5$ & Benchmark $(\varepsilon=0.75)$ & $\varepsilon=1.5$ \\
\hline Data & -2.95 & -2.95 & -2.95 \\
No TFP growth in Agriculture & 0.49 & 0.26 & 0.30 \\
No TFP growth in Manufacturing & -3.23 & -3.16 & -2.93 \\
No TFP growth in Services & -2.83 & -2.63 & -2.55 \\
No Wage Wedges & -3.03 & -3.07 & -2.99 \\
& & & \\
Mexico & $\varepsilon=0.5$ & Benchmark $(\varepsilon=0.75)$ & $\varepsilon=1.5$ \\
\hline Data & -2.45 & -2.45 & -2.45 \\
No TFP growth in Agriculture & 0.02 & 0.14 & 0.23 \\
No TFP growth in Manufacturing & -2.45 & -2.45 & -2.44 \\
No TFP growth in Services & -2.22 & -2.29 & -2.46 \\
No Wage Wedges & -3.08 & -3.08 & -2.51 \\
& & & \\
Brazil & $\varepsilon=0.5$ & Benchmark $(\varepsilon=0.75)$ & $\varepsilon=1.5$ \\
\hline Data & -2.46 & -2.46 & -2.46 \\
No TFP growth in Agriculture & 0.09 & -0.17 & 0.21 \\
No TFP growth in Manufacturing & -2.61 & -2.58 & -2.46 \\
No TFP growth in Services & -2.17 & -2.32 & -2.39 \\
No Wage Wedges & -2.75 & -2.73 & -2.50 \\
\hline & & &
\end{tabular}

Regardless of the elasticity, TFP growth in agriculture remains the most importance 
force for labor moving from agriculture to manufacturing and services. When TFP in agriculture is held constant, labor migration out of agriculture either occurs at a much slower pace or completely stops. TFP growth in manufacturing and services continues to have very little impact on labor allocation across sectors.

For each elasticity, removing the wage wedges increases the speed at which labor migrates out of agriculture. Moreover, the marginal effect appears to correlate with the elasticity. That is, the wage wedges are more distortionary when consumption goods are complements than when they are substitutes. Take India for example. When $\varepsilon=0.5$, removing the wage wedges speeds up labor migration out of agriculture by 0.2 percent annually. In the case $\varepsilon=1.5$, the effect is negligible. In sum, the main quantitative results are robust with respect to changes in the elasticity of substitution over a wide spectrum.

\section{Conclusion}

One of the fundamental questions in economics is why some countries are richer than others. The main reasons for low income in developing countries are high employment and simultaneously low productivity in agriculture (Caselli, 2005). Hence, understanding the determinants of structural change, and in particular that of labor migration from low-productivity agriculture to high-productivity manufacturing and services, is a key step towards understanding cross-country income difference. It is further observed that labor markets in many developing countries are subject to distortions that act as barri-

ers to labor moving out of agriculture. These observations motivate the question asked in this paper: what is the relative importance of sectoral productivity and labor market distortions for structural change?

I first use a model to infer that labor market distortions are systematic in three developing countries: India, Mexico and Brazil. In contrast, the US has a largely frictionless 
labor market. The magnitude of distortions in the three developing countries is quite large - an individual working in agriculture earns only half the wage of an identical individual in manufacturing. Under the presence of these labor market distortions, I find that TFP growth in agriculture drives most of the decline in its share of labor. Second, despite their large magnitude at face value, labor market distortions have limited effects on labor allocation across sectors or aggregate output.

\section{References}

Acemoglu, D. and V. Guerrieri (2008). Capital Deepening and Nonbalanced Economic Growth. Journal of Political Economy 116(3), 467-498.

Alvarez-Cuadrado, F. and M. Poschke (2011). Structural Change Out of Agriculture: Labor Push versus Labor Pull. American Economic Journal: Macroeconomics 3(3), 127-58.

Atkeson, A. and M. Ogaki (1996). Wealth-varying Intertemporal Elasticities of Substitution: Evidence from Panel and Aggregate Data. Journal of Monetary Economics 38(3), $507-534$.

Besley, T. and R. Burgess (2004). Can Labor Regulation Hinder Economic Performance? Evidence from India. The Quarterly Journal of Economics 119(1), 91-134.

Betts, C. M., R. Giri, and R. Verma (2013). Trade, Reform, and Structural Transformation in South Korea. Working Paper, University of Southern California.

Buera, F. J. and J. P. Kaboski (2009). Can Traditional Theories of Structural Change Fit the Data? Journal of the European Economic Association 7(2-3), 469-477.

Cai, W. and M. Pandey (2013a). The Agricultural Productivity Gap in Europe. De- 
partmental Working Papers 2013-05, The University of Winnipeg, Department of Economics.

Cai, W. and M. Pandey (2013b). Size-Dependent Labor Regulations and Structural Transformation in India. Economics Letters 119(3), 272-275.

Cao, K. H. and J. A. Birchenall (2013). Agricultural productivity, structural change, and economic growth in post-reform China. Journal of Development Economics 104, 165-180.

Caselli, F. (2005). Accounting For Cross Country Income Differences. In P. Aghion and S. D. Durlauf (Eds.), Handbook of Economic Growth, pp. 679-741. ELSEVIER.

Chari, V. V., P. J. Kehoe, and E. R. McGrattan (2007). Business cycle accounting. Econometrica 75(3).

Cheremukhin, A., M. Golosov, S. Guriev, and A. Tsyvinski (2013, September). Was Stalin Necessary for Russia's Economic Development? Working Paper 19425, National Bureau of Economic Research.

Cheremukhin, A., M. Golosov, S. Guriev, and A. Tsyvinski (2014). The Economy of People's Republic of China from 1953. Working paper, Federal Reserve Bank of Dallas.

Dekle, R. and G. Vandenbroucke (2012). A Quantitative Analysis of China's Structural Transformation. Journal of Economic Dynamics and Control 36(1), 119-135.

Dennis, B. N. and T. B. Iscan (2009). Engel versus Baumol: Accounting for structural change using two centuries of U.S. data. Explorations in Economic History 46(2), 186-202.

Duarte, M. and D. Restuccia (2010). The Role of the Structural Transformation in Aggregate Productivity. The Quarterly Journal of Economics 125(1), 129-173. 
Gollin, D., D. Lagakos, and M. E. Waugh (2013). The Agricultural Productivity Gap. Quarterly Journal of Economics. Forthcoming.

Gollin, D., S. Parente, and R. Rogerson (2002, May). The Role of Agriculture in Development. American Economic Review 92(2), 160-164.

Gollin, D., S. L. Parente, and R. Rogerson (2004). Farm work, Home Work and International Productivity Differences. Review of Ecconomic Dynamics 7(4), 827-850.

Gollin, D., S. L. Parente, and R. Rogerson (2007). The Food Problem and the Evolution of International Income Levels. Journal of Monetary Economics 54(4), 1230-1255.

Herrendorf, B., R. Rogerson, and A. Valentinyi (2013a, April). Growth and Structural Transformation. Working Paper 18996, National Bureau of Economic Research.

Herrendorf, B., R. Rogerson, and A. Valentinyi (2013b). Two Perspectives on Preferences and Structural Transformation. American Economic Review 103(7), 2752-89.

Herrendorf, B. and T. Schoellman (2012). Why is Measured Productivity so Low in the Agriculture. Working paper, Arizona State University.

Herrendorf, B. and T. Schoellman (2014). Wages, Human Capital, and Structural Transformation. Working paper, Arizona State University.

IPUMS-International (2014). Minnesota Population Center. Integrated Public Use Microdata Series, International: Version 6.3. [Machine-readable database].

King, M., S. Ruggles, J. T. Alexander, S. Flood, K. Genadek, M. B. Schroeder, B. Trampe, and R. Vick (2010). Integrated Public Use Microdata Series, Current Population Survey: Version 3.0. [Machine-readable database]. 
Kongsamut, P., S. T. Rebelo, and D. Xie (2001). Beyond Balanced Growth. Review of Economic Studies 68(4), 869-882.

Lagakos, D. and M. E. Waugh (2013, April). Selection, Agriculture, and Cross-Country Productivity Differences. American Economic Review 103(2), 948-80.

Machicado, C. G., F. Rioja, and A. Saravia (2012). Productivity, Structural Change, and Latin American Development. Development Research Working Paper Series 03/2012, Institute for Advanced Development Studies.

Ngai, L. R. and C. A. Pissarides (2007). Structural Change in a Multisector Model of Growth. American Economic Review 97(1), 429-443.

Restuccia, D., D. T. Yang, and X. Zhu (2008). Agriculture and Aggregate Productivity: A Quantitative Cross-country Analysis. Journal of Moneytary Economics 55(2), 234-250.

Rosenzweig, M. R. and K. I. Wolpin (1993). Credit Market Constraints, Consumption Smoothing, and the Accumulation of Durable Production Assets in Low-Income Countries: Investment in Bullocks in India. Journal of Political Economy 101(2), 223-44.

Rostow, W. W. (1960). The Stages of Economic Growth: A Non-Communist Manifesto. Cambridge, UK: Cambridge University Press.

Sposi, M. (2012). Evolving Comparative Advantage, Structural Change, and the Composition of Trade. Working Paper, Federal Reserve Bank of Dallas.

Swiecki, T. (2013). Determinants of Structural Change. Working Paper, University of British Columbia.

Teignier, M. (2012). The Role of Trade in Structural Transformation. Working Paper, Universitat de Barcelona. 
Timmer, M. P. and G. J. de Vries (2009). Structural Change and Growth Accelerations in Asia and Latin America: A New Sectoral Data Set. Cliometrica 3(2), 165-190.

Uy, T., K.-M. Yi, and J. Zhang (2013). Structural Change in an Open Economy. Journal of Monetary Economics 60(6), 667-82.

Verma, R. (2012). Can Total Factor Productivity Explain Value Added Growth in Services? Journal of Development Economics 99(1), 163 - 177.

Vollrath, D. (2013, March). The Efficiency of Human Capital Allocations in Developing Countries. Working Papers 201307956, Department of Economics, University of Houston. 


\section{APPENDIX}

\section{A Sectoral Human Capital}

\section{A.1 Wage Regression}

Micro data for India, Mexico and Brazil is from IPUMS-International (2014), and for the US IPUMS-CPS (King et al., 2010). There are five samples for India (1983, 1987, 1993, 1999, 2004) , six for Mexico (1960, 1970, 1990, 1995, 2000, 2010) and five for Brazil (1960, 1970, 1980, 1991, 2000). For the US, samples are March supplements to current population survey that run from 1962 to 2013, expect for 1963.

Samples are further restricted to include individuals between age 18 and 65 with non-negative wage and salary income, positive hours of work, and information on years of schooling or educational attainment. Individuals are identified as employees or selfemployed by their "class of workers". Generally only employees report wage income. Self-employed either do not report income or their reported income is hard to interpret and is thus ignored. Hourly wage is calculated as total income divided by hours of work. I calculate years of experience as age - years of schooling - 6 .

I run OLS regression of the logarithm of wage for employees on their years of schooling, years of experience, years of experience squared, and gender. The recovered coefficients are then used to compute human capital for all individuals. Several remarks are in order. First and most importantly, the wage regressions are run separately for each sector and for each country. That is, the estimated Mincer returns are country- and sectorspecific. As emphasized in Herrendorf and Schoellman (2012), differences in Mincer returns across sectors are an important factor behind differences in sectoral human capital.

Second, the wage regressions include only employees and, hence, exclude self-employed. 
However, the same Mincer returns are used to calculate human capital for both employees and self-employed within a sector who have sufficient information. Implicitly, it is assumed that self-employed individuals would earn the same income as employees who have the same education and experience. This is reasonable absent systematic self-selection (in either direction) into self-employment. It is important to include selfemployed in a model of structural change because self-employed typically account for more than half of the labor force in agriculture in virtually every country.

Lastly, wage and salaries income are not available for certain censuses. India has income data for each sample. Mexico, on the other hand, has income information only for the 1990 and 2000 samples. Brazil has income information only for the 1991 and 2000 samples. For Mexico, I apply the Mincer returns from the wage regression with 1990 data to 1960 and 1970 samples. And I apply the returns from the wage regression with 2000 data to 1995 and 2010 samples. For Brazil, the returns from regression with 1991 data are applied to samples prior to 1991. For the US, I divide the sample into four decades: 1960, 1970, 1980, 1990. I run wage regressions using pooled samples from the same decade, and use the estimated returns to calculate human capital for each year within the same decade. 